07.2;09.2

\title{
Увеличение КПД концентраторных фотоэлектрических модулей при использовании фоконов в качестве вторичных оптических концентраторов
}

\author{
(ㄱ Н.Ю. Давидюк, Д.А. Малевский, П.В. Покровский, Н.С. Потапович, Н.А. Садчиков, А.В. Чекалин
}

Физико-технический институт им. А.Ф. Иоффре РАН, Санкт-Петербург, Россия

『E-mail: chekalin@mail.ioffe.ru

Поступило в Редакцию 4 декабря 2019г.

В окончательной редакции 4 декабря 2019г.

Принято к публикации 6 декабря 2019г.

Разработаны концентраторные фотоэлектрические модули на основе линз Френеля и вторичных концентраторов - полых фоконов из листового алюминия. Для увеличения КПД преобразования солнечного излучения определена оптимальная конфигурация фоконов и исследованы фотоэлектрические характеристики модулей. Использование фоконов обеспечило увеличение допустимого угла разориентации модуля с $\pm 0.45^{\circ}$ (без фокона) до $\pm 0.8^{\circ}$ (с фоконом) и увеличение КПД модуля с $29.2 \%$ (без фокона) до $32.8 \%$ (с фоконом).

Ключевые слова: концентраторная фотоэнергетика, линзы Френеля, каскадные фотопреобразователи, вторичные оптические концентраторы.

DOI: 10.21883/PJTF.2020.05.49107.18140

Вследствие высокой стоимости высокоэффективных каскадных фотоэлектрических преобразователей (ФЭП) их применение в наземной солнечной электроэнергетике возможно только при совместном использовании с недорогими оптическими концентраторами, обеспечивающими уменьшение площади и стоимости ФЭП в 500-1000 раз. Высокие значения КПД преобразования солнечного излучения в каскадных ФЭП, превышающие 40\%, сохраняются при кратностях концентрирования излучения 500-1000 „солнц“.

Высокие кратности концентрирования достигаются за счет совместного использования первичных и вторичных оптических концентраторов (ВОК). В качестве первичных концентраторов излучения наибольшее распространение получили линзы Френеля [1]. Использование вторичного концентратора позволяет увеличить кратность концентрирования излучения, улучшить разориентационные характеристики концентраторного фотоэлектрического модуля (КФЭМ) и уменьшить потери, связанные с хроматической аберрацией [2] и неравномерным распределением излучения по поверхности фотоэлектрических преобразователей [3]. В качестве ВОК обычно используются плосковыпуклые линзы или конические отражатели, изготовленные либо из полированного листового алюминия, либо из массива стекла с полированными боковыми поверхностями [4-7].

Основной задачей настоящей работы является определение наиболее оптимальных параметров вторичных концентраторов для фотоэлектрических модулей, а также последующее изготовление и исследование модулей с такими концентраторами.

Для увеличения энергоэффективности КФЭМ были разработаны ВОК в виде полой перевернутой усеченной пирамиды с зеркальным отражением от внутренней поверхности боковых стенок (рис. 1).

Для измерения параметров разработанных модулей был использован лабораторный импульсный измери-

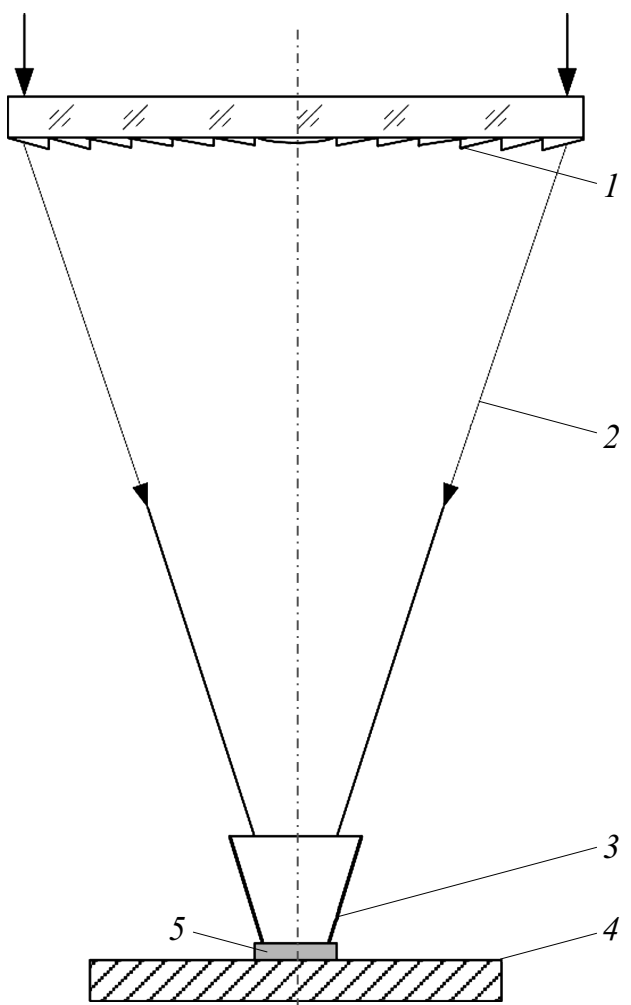

Рис. 1. Схема концентраторного модуля, включающего линзу Френеля, фокон и каскадный солнечный элемент. 1 - линза Френеля, $2-$ солнечные лучи, 3 - вторичная оптика, $4-$ теплоотвод, $5-$ солнечный элемент. 
Таблица 1. Значения КПД преобразования излучения и электрической мощности, генерируемых в модуле в режиме оптимальной нагрузки с фоконами разной высоты при углах наклона боковых граней $22^{\circ}$

\begin{tabular}{c|c|c|c|c|c}
\hline \multirow{2}{*}{ Параметр } & \multicolumn{4}{|c|}{ Высота фокона, $\mathrm{mm}$} & \multirow{2}{*}{ Без фокона } \\
\cline { 2 - 5 } & 10 & 17 & 22 & 30 & \\
\hline КПД преобразования, \% & 28.7 & 29.5 & 29.8 & 30.0 & 26.8 \\
Электрическая мощность, $\mathrm{W}$ & 4.13 & 4.25 & 4.29 & 4.32 & 3.84
\end{tabular}

Таблица 2. Значения КПД преобразования излучения и электрической мощности, генерируемых в модуле в режиме оптимальной нагрузки с фоконами высотой $20 \mathrm{~mm}$ при разных углах наклона граней

\begin{tabular}{c|c|c|c|c|c|c}
\hline \multirow{2}{*}{ Параметр } & \multicolumn{5}{|c|}{ Угол наклона граней, deg } & \multirow{2}{*}{ Без фокона } \\
\cline { 2 - 6 } & 17 & 20 & 22 & 25 & 30 & \\
\hline КПД преобразования, \% & 28.7 & 29.3 & 29.8 & 29.7 & 29.3 & 26.8 \\
Электрическая мощность, W & 4.16 & 4.23 & 4.29 & 4.28 & 4.22 & 3.84
\end{tabular}

тельный комплекс, в котором источником излучения служила импульсная ксеноновая лампа, формирующая световой поток, идентичный идущему от солнечного диска (спектр AM1.5D). Измерения электрических параметров выполнялись при энергетической освещенности $1000 \mathrm{~W} / \mathrm{m}^{2}$ и температуре окружающей среды $25^{\circ} \mathrm{C}$.

КФЭМ включает линзу Френеля размером $120 \times 120 \mathrm{~mm}$ с фокусным расстоянием $175 \mathrm{~mm}$ и электрогенерирующую плату с ФЭП, скрепленные между собой при помощи алюминиевых стенок. На электрогенерирующей плате в фокальном пятне закреплен каскадный ФЭП GaInP/GaAs/Ge c размером фотоприемной площадки $5.5 \times 5.5 \mathrm{~mm}$ с установленным на нем фоконом (рис. 1).

В качестве материала для фоконов был использован листовой анодированный алюминий толщиной $0.4 \mathrm{~mm}$ с высокой отражающей способностью, равной 96-98\%. Изготовление образцов фоконов осуществлялось посредством получения заготовок нужного профиля с помощью лазерной резки с последующим формированием фоконов пирамидальной формы. Было изготовлено несколько типов фоконов с различными параметрами: высотой $(h)$ от 10 до $30 \mathrm{~mm}$, углом наклона граней $(\alpha)$ от 17 до $30^{\circ}$ и размером выходной апертуры $4.5 \times 4.5 \mathrm{~mm}$.

В табл. 1 приведены значения КПД преобразования излучения и электрической мощности, генерируемых в модуле в режиме оптимальной нагрузки при установке фоконов разной высоты с углом наклона граней фоконов $\alpha=22^{\circ}$. Увеличение высоты фокона приводит к росту КПД и генерируемой модулем мощности, что обусловлено увеличением степени перехвата излучения линзы фоконом.

В табл. 2 приведены значения КПД преобразования излучения и электрической мощности, генерируемых в модуле в режиме оптимальной нагрузки при использовании фоконов высотой $20 \mathrm{~mm}$ с разными углами наклона

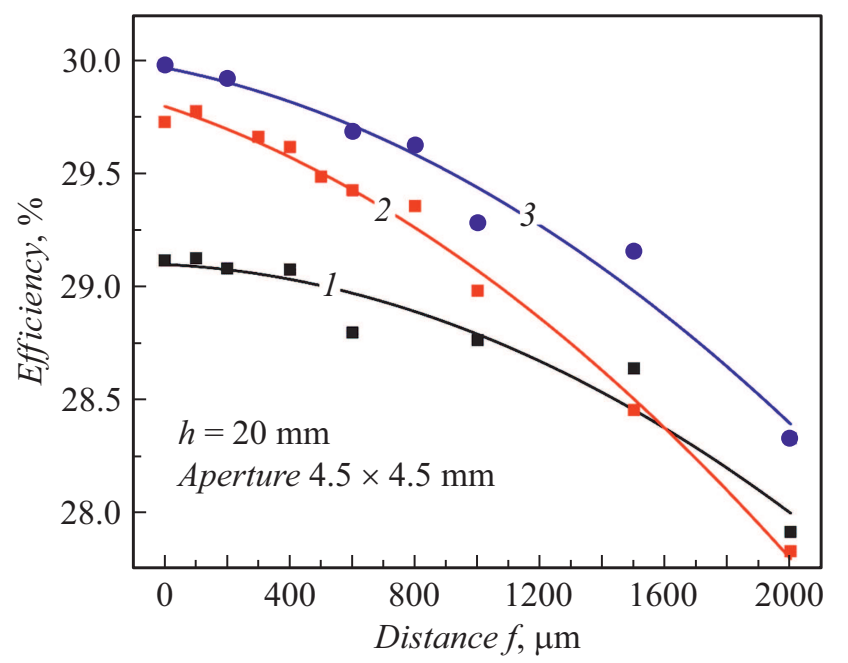

Рис. 2. Зависимости значений КПД модулей от расстояния $(f)$ нижней грани фоконов от поверхности ФЭП для фоконов высотой $h=20 \mathrm{~mm}$ с углом наклона боковых граней $\alpha=20$ (1), 22 (2) и $25^{\circ}(3)$.

граней. Из этой таблицы видно, что максимум мощности и КПД модуля достигается при использовании фоконов с $\alpha=22$ и $25^{\circ}$. Использование фоконов с бо́льшими углами наклона граней ведет к увеличению количества зеркальных отражений от стенок фокона и увеличению оптических потерь.

При использовании фоконов необходим их монтаж в непосредственной близости от поверхности ФЭП. Были выполнены исследования влияния высоты установки фокона над поверхностью ФЭП на эффективность работы модуля. Для измерений были использованы фоконы с тремя разными углами наклона граней $(\alpha=20,22$ и $25^{\circ}$ ). На рис. 2 представлены измеренные значения КПД преобразования солнечного излучения в модуле 


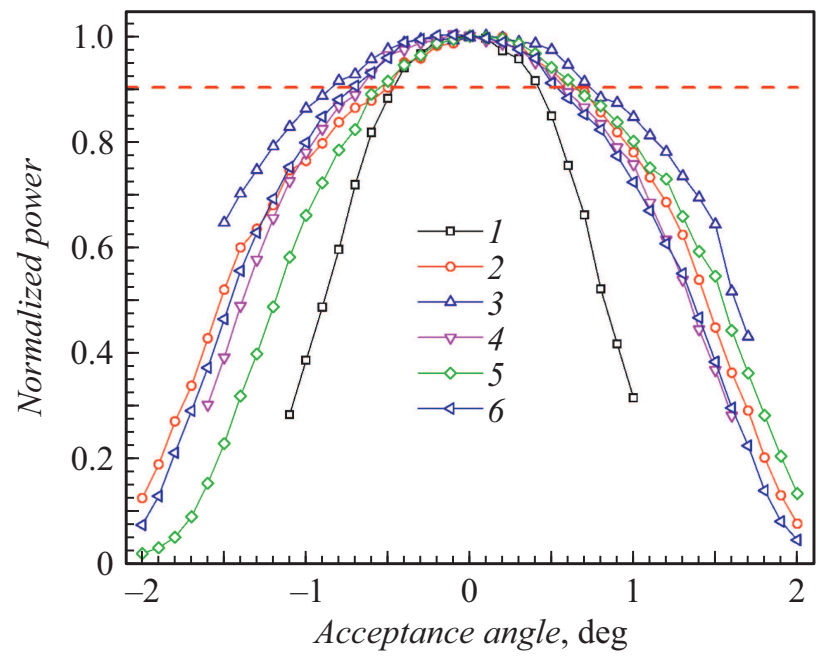

Рис. 3. Разориентационные кривые модулей: без фокона (1); с фоконом с углом наклона граней $\alpha=20^{\circ}$, расположенным вПлотную к ФЭП $(f=0)(2)$; с фоконом с углом наклона граней $\alpha=22^{\circ}$ и $f=0(3)$; с фоконом с углом наклона граней $\alpha=25^{\circ}$ и $f=0(4)$; с фоконом с углом наклона граней $\alpha=22^{\circ}$ и расстоянием от ФЭП $f=200 \mu \mathrm{m}(5)$; с фоконом с углом наклона граней $\alpha=25^{\circ}$ и расстоянием от ФЭП $f=200 \mu \mathrm{m}(6)$.

при использовании фоконов разной конфигурации и изменении зазора $(f)$ между нижней гранью фокона и поверхностью ФЭП. Увеличение зазора вплоть до $f=400 \mu \mathrm{m}$ приводит к незначительному уменьшению КПД модуля.

Были выполнены исследования разориентационных характеристик модуля с линзой Френеля размером $120 \times 120 \mathrm{~mm}$ и фоконами различной формы. На рис. 3 представлены разориентационные кривые для модуля без вторичной оптики, а также с фоконами трех размеров, установленными как вплотную к фотоэлементу $(f=0)$, так и на расстоянии $f=200 \mu$ т от поверхности ФЭП. „Допустимый“ угол разориентации, определяемый по разориентационным кривым на уровне 0.9 от максимума, для модуля без вторичной оптики составляет $\pm 0.45^{\circ}$. Наибольший ,допустимый“ угол разориентации $\pm 0.8^{\circ}$ имеет место в модуле с фоконом с углом наклона граней $\alpha=22^{\circ}$, установленным вплотную к ФЭП $(f=0)$.

При освещении имитатором солнечного излучения максимальный КПД модуля без фокона составил 29.2\%. Добавление фокона обеспечило увеличение КПД модуля до $32.8 \%$.

Таким образом, конфигурация фоконов высотой $20-22 \mathrm{~mm}$ с углом наклона его граней $22-25^{\circ}$ оказалась наиболее оптимальной. Использование в КФЭМ фоконов с такими параметрами обеспечило увеличение КПД преобразования солнечного излучения модулей на 3 абсолютных процента и улучшило их разориентационные характеристики с $\pm 0.45^{\circ}$ до $\pm 0.8^{\circ}$.

\section{Конфликт интересов}

Авторы заявляют, что у них нет конфликта интересов.

\section{Список литературы}

[1] Rumyantsev V.D. // Springer Series in Optical Sciences. 2007. V. 130. P. 151-174.

[2] Dominguez C., Anton I., Sala G., Askins S. // Prog. Photovolt.: Res. Appl. 2013. V. 21. N 7. P. 1478-1488.

[3] Victoria M., Herrero R., Dominguez C., Antón I., Askins S., Sala G. // Prog. Photovolt.: Res. Appl. 2013. V. 21. N 3. P. 308-318.

[4] Araki K., Kondo M., Uozumi H., Yamaguchi M. // 3rd World Conf. on photovoltaic and energy conversion. Osaka, Japan, 2003. V. 1. P. $853-856$.

[5] Jaus J., Nitz P., Peharz G., Siefer G., Schult T., Wolf O., Passig M., Gandy T., Bett A.W. // 33rd IEEE Photovoltaic Specialists Conference. IEEE, 2008. P. 1-5.

[6] Rumyantsev V.D., Davidyuk N.Yu., Ionova E.A., Larionov V.R., Malevskiy D.A., Pokrovskiy P.V., Sadchikov N.A., Andreev V.M. // Proc. of the 5th Int. Conf. on solar concentrators for the generation of electricity. Palm Desert, California, USA, 2008.

[7] Давидюк Н.Ю., Ионова Е.А., Малевский Д.А., Румянцев В.Д., Садчиков Н.А. // ЖТФ. 2010. Т. 80. В. 7. С. 90-95. 